Introduction: Gynaecological cancers, including cervical cancer, often require a multidisciplinary approach that includes external beam radiotherapy, chemotherapy, and/or surgical treatment. Biological parameters of the tumour evaluated in ${ }^{18} \mathrm{~F}$-FDG-PET/CT are used for target volume delineation in radiotherapy planning. The choice of segmentation method may affect the assessment of metabolic tumour volume (MTV) in ${ }^{18} \mathrm{~F}-\mathrm{FDG}-\mathrm{PET} / \mathrm{CT}$.

Aim of the study: To find the optimal segmentation method for the assessment of primary MTV in ${ }^{18}$ F-FDG-PET/ CT in cervical cancer patients for radiotherapy planning.

Material and methods: Retrospective analysis was performed on a group of 30 patients with newly diagnosed, histologically confirmed cervical cancer. The primary MTVs were assessed by SUV max $_{\text {max }}$ and SUV mean $_{\text {malues; three }}$ segmentation methods were used to assess the primary MTV: constant threshold of SUV $V_{\text {max }}$ of 2.5, threshold of SUV $35 \%$, and threshold of SU$\mathrm{V}_{\max } 45 \%$. The MTVs were compared with the tumour volumes obtained in magnetic resonance imaging (MRI), which was the "gold standard", to select the best optimal segmentation method reflecting the tumour size. Wilcoxon-Mann-Whitney and t-test were used for statistical analysis.

Results: Depending on the segmentation method chosen, significant differences in the MTVs were obtained $(p<0.001)$. The highest volumes were obtained using the method based

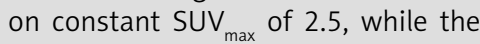
smallest in case of threshold of SUV of $45 \%$. Regarding the volume determined by MRI, a $35 \%$ SUV $_{\text {max }}$ threshold was chosen as the most reliable method.

Conclusions: The choice of appropriate segmentation method has a significant impact on the primary MTV assessment in ${ }^{18} \mathrm{~F}-\mathrm{FDG}$-PET/CT in patients with cervical cancer.

Key words: cervical cancer, segmentation, ${ }^{18} \mathrm{~F}$-fluorodeoxyglucose, PET/CT, SUV.

Contemp Oncol (Pozn) 2019; 23 (3): 183-186 DOI: https://doi.org/10.5114/wo.2019.89248

\section{The effect of different} segmentation methods on primary tumour metabolic volume assessed in ${ }^{18} \mathrm{~F}-\mathrm{FDG}-\mathrm{PET} / \mathrm{CT}$ in patients with cervical cancer, for radiotherapy planning

\author{
Paulina Cegła ${ }^{1}$, Ewa Burchardt ${ }^{2,3}$, Ewa Wierzchosławska ${ }^{2,4}$, Andrzej Roszak ${ }^{2,3}$, \\ Witold Cholewiński ${ }^{1,2}$ \\ ${ }^{1}$ Department of Nuclear Medicine, Greater Poland Cancer Centre, Poznan, Poland \\ ${ }^{2}$ Chair and Department of Electroradiology, Poznan University of Medical Sciences, Poland \\ ${ }^{3}$ Department of Radiotherapy and Oncological Gynaecology, Greater Poland Cancer \\ Centre, Poznan, Poland \\ ${ }^{4}$ Department of Radiology, Greater Poland Cancer Centre, Poznan, Poland
}

\section{Introduction}

In 2014 cervical cancer was the sixth most common gynaecological cancer diagnosed, seventh in terms of mortality among malignant tumours in Poland [1], and ranks fourth for both incidence and mortality worldwide [2]. External beam radiotherapy is one of the treatment options of this cancer and is more commonly used as either an independent method of treatment or supplementary to chemotherapy or surgery. Appropriate determination of the primary tumour boundaries in the treatment planning system plays a pivotal role not only in minimising the dose to the surrounding organs at risks, but also in minimising the risk of recurrence [3].

Metabolic tumour volume (MTV) assessed by PET/CT imaging using ${ }^{18} \mathrm{~F}$-fluorodeoxyglucose ( $\left.{ }^{18} \mathrm{~F}-\mathrm{FDG}\right)$, a fluorine-radiolabelled glucose analogue, helps to assess the size of the biologically active tumour [4]. Based on Otto Warburg's observation of increased glucose utilisation in tumour cells [4], the radiopharmaceuticals, which are captured similarly to glucose, e.g. ${ }^{18} \mathrm{~F}-\mathrm{FDG}$, can be used in the imaging of cancerous tumours $[5,6]$. The algorithm used to evaluate MTV in PET/CT can be based on: visual assessment, fixed maximum standardized uptake value $\left(S U V_{\max }\right)$, or the threshold method based on the percentage of SUV ${ }_{\max }$ [7].

The aim of the study was to assess the effect of different segmentation methods on primary metabolic tumour volume assessed in a ${ }^{18} \mathrm{~F}$-FDG-PET/CT study in patients with cervical cancer.

\section{Material and methods}

A retrospective analysis was performed on 30 newly diagnosed patients with cervical cancer (mean age: $55 \pm 11$ years, range: $82-28$ years), admitted to the Department of Radiotherapy and Gynaecological Oncology at the Greater Poland Cancer Centre between January 2012 and October 2014 for radiotherapy planning. Each patient underwent physical and ultrasound gynaecological examination with an abdominal and vaginal probe. Additionally, magnetic resonance imaging (MRI) was performed to determine the stage of disease and for radiotherapy planning. ${ }^{18} \mathrm{~F}-\mathrm{FDG}-\mathrm{PET} / \mathrm{CT}$ examination was performed in the Nuclear Medicine Department in Greater Poland Cancer Centre on a Gemini TF 16 PET/CT scanner prior to treatment, within a month 
of diagnosis. The procedure was performed in patients who were fasting for at least five hours before the test (mean glucose level was $93 \pm 18 \mathrm{mg} / \mathrm{dl}$ ) in order to avoid problems with the interpretation of the study. The patients after the administration of the isotope stayed in a darkened room at room temperature to rest without any excessive physical activity. Acquisition was performed an average of 60 min after intravenous injection of $374 \pm 75 \mathrm{MBq}$ of ${ }^{18} \mathrm{~F}-\mathrm{FDG}$. The study protocol extended from the calvaria to the mid-thigh and included $10-12$ bed positions, with $1.5 \mathrm{~min}$ per bed position and cutting scans $5 \mathrm{~mm}$ thick. The study began with the implementation of simultaneous, low-dose computed tomography (CT), beginning in the brain area, through the chest, abdominal cavity, and pelvis to better visualise the areas with increased uptake and to correct attenuation. Afterwards, the PET acquisition was performed without changing the patient's position. Reconstructions were performed at an EBW workstation using the time-of-flight (TOF) technique.

As a result of the PET/CT analysis, areas with increased metabolism considered as active tumour foci were indicated. The primary tumour metabolic activity was assessed by SUV ${ }_{\text {max }}$ and SUV ${ }_{\text {mean }}$, and calculated from the formula:

$$
\text { SUV }=\frac{r}{a / w}
$$

where $r$ is the radioactivity concentration $(\mathrm{kBq} / \mathrm{ml})$ measured by the PET scanner within a region of interest (ROI), $a$ is the decay-corrected amount of injected ${ }^{18} \mathrm{~F}-\mathrm{FDG}(\mathrm{MBq})$, and $w$ is the patient's weight $(\mathrm{kg})$.

Metabolic volumes of the primary tumour were calculated using three segmentation methods based on:

- SUV $_{\text {max }}$ value (2.5),

- threshold of SUV max $35 \%$ (Th 35\%),

- threshold of SUV ${ }_{\max } 45 \%$ (Th 45\%).

The volumes taken from ${ }^{18} \mathrm{~F}$-FDG-PET/CT examination were compared with the volumes obtained in MRI, which was treated as a "gold standard" because it is the most precise imaging method for the assessment of the primary tumour volume in cervical cancer [8], to select the optimal segmentation method in PET. Volume measurements were calculated automatically in dedicated workstations in the Nuclear Medicine and Radiology Department, without user modifications.

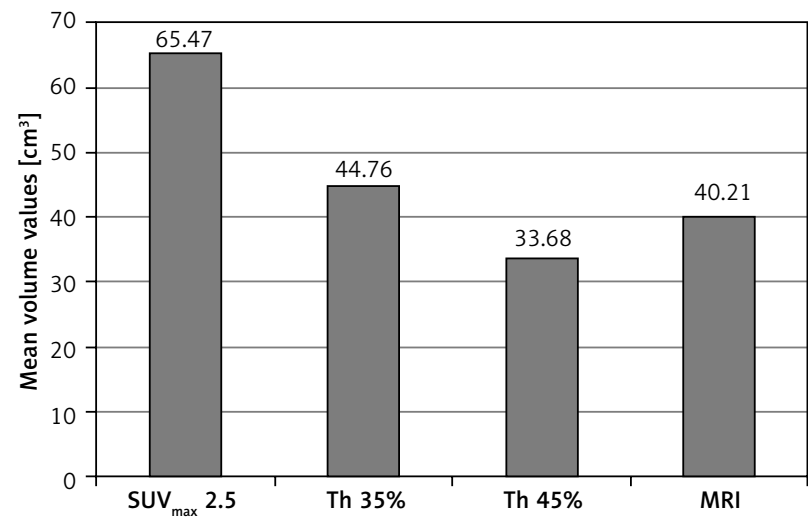

Fig. 1. The effect of different segmentation methods on the volume of primary tumour assessed in the whole group
Normality of the data distribution was assessed using Kolmogorov-Smirnov test or W Shapiro-Wilk test. For statistical analysis the Wilcoxon-Mann-Whitney and $t$-test were used. Pearson coefficients were used to estimate correlation between parameters. All statistical analysis was performed in the extended STATISTICA application version 13.1 with a medical package, created by StatSoft Polska 2014, as well as the extended Microsoft Excel 2013 application with the Analyse-it package. The mean values of SUV ${ }_{\text {max }}$, SUV $_{\text {mean }}$, and MTV parameters were evaluated using three segmentation methods. The value of $p<0.05$ was considered statistically significant.

\section{Results}

The results of the PET/CT study divided the 30 patients into three subgroups: A - disease limited only to the cervix (33\%), B - disease limited to the cervix and iliac lymph nodes (37\%), C-disseminated disease to the lymph nodes above aorta bifurcation or other organs (30\%). In all analyzed groups non-keratinizing squamous cell carcinoma (SCC) was diagnosed.

The analysis of the results performed in the whole group of patients, using different segmentation methods, showed significant differences $(p<0.001)$ in the mean volumes - the largest tumour volumes were obtained using the method based on SUV $\max 2.5\left(\right.$ MTV $\left.=65.47 \mathrm{~cm}^{3}\right)$, and the smallest with the method based on threshold of SU$V_{\max } 45 \%\left(M T V=33.68 \mathrm{~cm}^{3}\right)$, as shown in Figure 1. Different tumour volumes also resulted in a differentiation in metabolic activity parameters measured by SUV mean $_{\text {val- }}$

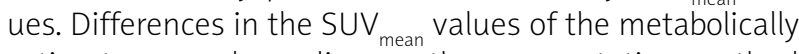
active tumour, depending on the segmentation method applied, reached 50\% (Fig. 2). Depending on the chosen segmentation method, statistically significant differences $(p<0.001)$ were demonstrated between SUV ${ }_{\text {mean }}$ and MTV values for all three groups (Table 1).

In comparison with MRI, the highest correlation ( $r=$ $0.85, p=0.01$ ) in reading the primary tumour metabolic volumes in PET/CT was achieved using the threshold method of segmentation based on $35 \%$ of SUV max $_{\text {. In the }}$ case of the SUV $V_{\max } 45 \%$ threshold and constant value of SUV $_{\max } 2.5$, the correlation was lower $(r=0.75, p=0.03$ and $r=0.46, p=0.07$, respectively).

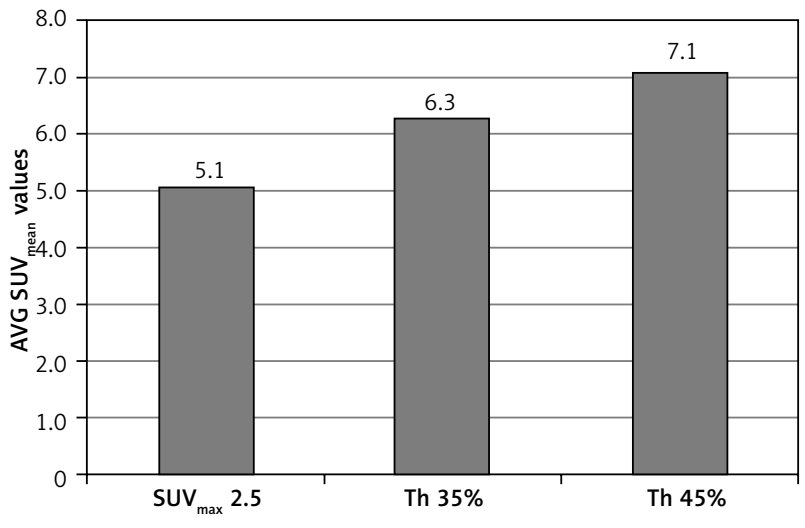

Fig. 2. Average $S U V_{\text {mean }}$ values depending on the chosen segmentation method in the whole group 
Table 1. The influence of different segmentation methods on the evaluated parameters depending on the group

\begin{tabular}{|c|c|c|c|c|c|c|c|c|c|}
\hline & \multicolumn{3}{|c|}{ SUV $_{\max } 2.5$} & \multicolumn{3}{|c|}{ Th $35 \%$} & \multicolumn{3}{|c|}{ Th $45 \%$} \\
\hline & $A$ & B & $C$ & $A$ & B & $C$ & $A$ & B & $C$ \\
\hline $\mathrm{SUV}_{\max }$ & $11.7 \pm 4.9$ & $13.1 \pm 4.7$ & $11.1 \pm 4.4$ & $12.1 \pm 5.1$ & $13.1 \pm 4.7$ & $11.1 \pm 4.4$ & $12.5 \pm 5.6$ & $13.1 \pm 4.7$ & $11.1 \pm 4.4$ \\
\hline SUV $_{\text {mean }}$ & $4.8 \pm 1.1$ & $5.5 \pm 1.4$ & $4.8 \pm 1.3$ & $6.0 \pm 2.1$ & $6.9 \pm 2.6$ & $5.7 \pm 2.6$ & $6.9 \pm 2.3$ & $7.7 \pm 2.7$ & $6.4 \pm 2.8$ \\
\hline
\end{tabular}

A - disease limited to the cervix (33\%), B - disease limited to the cervix and iliac lymph nodes (37\%), $C$ - disseminated disease to the lymph nodes above aorta bifurcation or other organs (30\%)

\section{Discussion}

Determining the volume of the primary tumour is crucial in radiotherapy planning. Because the ${ }^{18} \mathrm{~F}$-FDG-PET/ CT examination is based on Warburg's observation of increased glucose consumption in malignant tumours, it is regarded as an effective method of determining the metabolic tumour volume of cancerous tissue $[9,10]$. According to Sridhar et al., metabolic volumes assessed by ${ }^{18} \mathrm{~F}-\mathrm{FDG}$ PET/CT are more reliable for large tumours $(\geq 10 \mathrm{ml})$ than for small tumours $(\leq 10 \mathrm{ml})$ [11]. In this study we did not observe such a dependence. The volumes of primary tumours were comparable to those from MRI imaging when

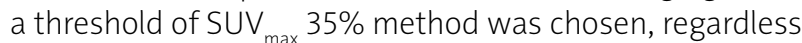
of the size of the primary tumour.

Many methods have been proposed for determining tumour volume in the ${ }^{18} \mathrm{~F}$-FDG-PET/CT study. One of them is the manual method in which a nuclear medicine specialist defines the border between tumour and normal tissue. This method largely depends on the selection of the right window for CT imaging as well as tumour and surrounding tissue characteristics. It is also dependent on the person evaluating the test, with a variability ranging from $5 \%$ to 45\% [11, 12]. Hatt et al. analyzed 25 patients with nonsmall cell lung cancer (NSCLC) and compared the volumes obtained with CT and PET. They showed that volumes obtained with CT $\left(55 \pm 74 \mathrm{~cm}^{3}\right)$ were significantly higher $(p<$ 0.0001 ) than those assessed in the PET study (ranging from $18 \pm 25$ to $47 \pm 76 \mathrm{~cm}^{3}$, depending on the chosen delineation method) [13]. The method based on 50\% threshold cut-off point proposed by $\mathrm{Wu}$ et al. led to the greatest underestimation of MTV, with errors up to $+1.8 \mathrm{~cm}(+32 \%)$ [14] Some authors have reported underestimation of tumour volumes assessed by SUV-based segmentation methods, especially in the case of small tumours, which is of particular importance when determining the size of lymph nodes or small primary lesions [15]. Our study showed the largest volumes in the segmentation method based on SUV ${ }_{\max }$ 2.5 values in all three groups of patients, which did not correlate with the volumes assessed by MRI. Currently, the threshold adaptive method is one of the most commonly used segmentation methods, among others in head and neck, lung, and cervical cancers [11].

Many authors suggest that MTV evaluated by ${ }^{18} \mathrm{~F}-\mathrm{FDG}$ PET/CT study is a predictor of the patient's outcome in solid tumours. Romesser et al. compared SUV $\mathrm{max}_{\text {max }}$ gross tumour volume (GTV) and MTV for disease control and survival in patients with head and neck squamous cell carcinoma (HNSCC) [16]. Using the Kaplan-Meier method they con- cluded that MTV and GTV are better prognostics factors

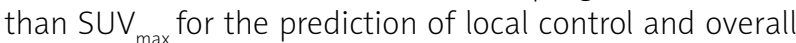
survival in HNSCC [16]. In addition, metabolic tumour volume has been shown to be a better prognostic parameter than SUV ${ }_{\max }$ itself in predicting patients' outcome, and it may become useful in clinical evaluation [17-19]. Miller and Grigsby noticed that the primary tumour volume determined using ${ }^{18} \mathrm{~F}$-FDG-PET affects both the overall survival $(p=0.003)$ and the time to detect the disease spread $(p=0.005)$ in patients with advanced cervical cancer [20].

Xu et al., in their analysis of 55 patients with planoepithelial cervical cancer, assessed the effect of different segmentation methods on the metabolic volumes obtained in the ${ }^{18} \mathrm{~F}$-FDG-PET/CT study in relation to the size of the tumour obtained from the pathologist [7]. Depending on the SUV $_{\text {max }}$ value, patients were divided into four subgroups, in which statistically significant differences were observed depending on the choice of the segmentation method ( $p<$ 0.005). Metabolic volumes assessed based on $20 \%$ and $30 \%$ thresholds overvalued, while the threshold $40 \%, 50 \%$, and $60 \%$ undervalued the results, in comparison with GTV assessed in pathological examination performed after radical hysterectomy. The most reliable results were obtained using the iterative adaptive segmentation algorithm [7]. Kim et al. compared MTV at threshold $40 \%$ in 45 patients with invasive cervical cancer with pathological and prognostic results [21]. The results showed that patients with MTV greater than $20 \mathrm{~cm}^{3}$ had a reduced disease-free survival time compared to those with MTV below $20 \mathrm{~cm}^{3}(p=0.029)$. Similar studies conducted by Ciernik et al. evaluated the use of PET/CT in the planning of radiotherapy, and $50 \% \mathrm{SUV}_{\max }$ turned out to be a reliable reflection with the tumour volume assessed in the CT technique [22]. Showalter et al. applied a 40\% threshold of SUV ${ }_{\max }$ to define the primary tumour diameter in the early stage of cervical cancer and found a significant positive correlation with the tumour diameter assessed by the pathologist $(r=0.757, p<0.0001)$ [23].

This study has a few limitations. The main one is the small number of patients. Secondly, ${ }^{18}$ F-FDG-PET/CT cannot precisely assess the severity of the primary tumour local infiltration, due to high physiological activity of the bladder and rectum. Also, physiological ${ }^{18} \mathrm{~F}$-FDG uptake is shown, e.g. in urinary tract, ovaries, and uterus during various phases of menstruation, which can mask the malignant lesions. False negative results might be gained in the case of small lesions $(<7 \mathrm{~mm}$ ) or different tumour subtypes (e.g. neuroendocrine tumour). False positive results could potentially be obtained in the case of inflammatory or infectious processes [24, 25]. 
MRI has limited value in the differentiation of metastatic lymph nodes from hyperplasia, in detecting microinvasion in nonenlarged lymph nodes, and for the evaluation of cervical stroma [26, 27]. The limitation in the evaluation of primary tumour size in MRI also includes the impossibility of margin definition, confusing with peritumoral reactions or scars and small tumours $(<1 \mathrm{~cm})$, which might be only visualised on early dynamic contrast-enhanced sequence (DCE) MRI as enhanced foci $[28,29]$.

\section{Conclusions}

In patients with cervical cancer the choice of appropriate segmentation method of primary tumour in ${ }^{18} \mathrm{~F}-\mathrm{FDG}$-PET/ $\mathrm{CT}$ has a significant impact on radiotherapy planning. The metabolic tumour volumes obtained in ${ }^{18} \mathrm{~F}$-FDG-PET/CT correlated best with MRI volumes when a threshold of $35 \%$ of the SUV ${ }_{\max }$ value was chosen as a segmentation method.

The authors declare no conflict of interest.

\section{References}

1. Wojciechowska U, Olasek P, Czauderna K, Didkowska J. Nowotwory złośliwe w Polsce w 2014 roku. Biuletyn Ministerstwa Zdrowia, Warszawa 2016.

2. Bray F, Ferlay J, Soerjomataram I, Siegel RL, Torre LA, Jemal A. Global cancer statistics, 2018: GLOBOCAN estimates of incidence and mortality worldwide for 36 cancers in 185 countries. CA Cancer J Clin 2018; 68: 394-424.

3. Prudy JA. Dose to normal tissues outside the radiation therapy patient's treated volume: a review of different radiation therapy techniques. Health Phys 2008; 95: 666-676.

4. Warburg O, Posener K, Negelein E. The metabolism of cancer cells Biochem Zeitschr 1924; 152; 129-169.

5. Minn H, Suilamo S, Seppälä J. Impact of PET/CT on planning of radiotherapy in head and neck cancer. Q J Nucl Med Mol Imaging 2010; 54: 521-532.

6. Dutta S, Nquyen NP, Vock J, et al. Image-guide radiotherapy and brachytherapy for cervical cancer. Front Oncol 2015; 5: 64.

7. Xu W, Yu S, Ma Y, Liu C, Xin J. Effect of different segmentation algorithms on metabolic tumor volume measured on ${ }^{18} \mathrm{~F}-\mathrm{FDG} \mathrm{PET} / \mathrm{CT}$ of cervical primary squamous cell carcinoma. Nucl Med Commun 2017; 3: 259-265.

8. Fields EC, Weiss E. A practical review of magnetic resonance imaging for the evaluation and management of cervical cancer. Radiat Oncol 2016; 11: 15

9. Burri RJ, Rangaswamy B, Kostakoglu L, Hoch B, Genden EM, Som PM, Kao J. Correlation of positron emission tomography standard uptake value and pathologic specimen size in cancer of the head and neck. Int J Radiat Oncol Biol Phys 2008; 71: 682-688.

10. Troost EG, Schinagl DA, Bussink J, Oyen WJ, Kaanders JH. Clinical evidence on PET-CT for radiation therapy planning in head and neck tumors. Radiother Oncol 2010; 96: 328-334.

11. Sridhar P, Mercier G, Tan J, Truong MT, Daly B, Subramaniam RM FDG PET Metabolic Tumor Volume Segmentation and Patholog ic Volume of Primary Human Solid Tumors. AJR Am J Roentgenol 2014; 202: 1114-1119.

12. Bowden P, Fisher R, Mac Manus M, et al. Measurement of lung tumor volumes using three-dimensional computer planning software. Int J Radiat OncolBiol Phys 2002; 53: 566-573.

13. Hatt M, Cheze-Le Rest C, van Baardwijk A, Lambin P, Pradier O, Vis vikis D. Impact of tumor size and tracer uptake heterogeneity in ${ }^{18} \mathrm{~F}$-FDG PET and CT non-small cell lung cancer tumor delineation. J Nucl Med 2011; 52: 1690-1697.

14. Wu K, Ung YC, Hornby J, et al. PET CT thresholds for radiotherapy target definition in non-small-cell lung cancer: how close are we to the pathologic findings? Int J Radiat Oncol Biol Phys 2010; 77: 699-706.

15. Hoetjes NJ, van Velden FH, Hoekstra OS, Hoekstra CJ, Krak NC, Lammertsma AA, Boellaard R. Partial volume correction strategies for quantitative FDG PET in oncology. Eur J Nucl Med Mol Imaging 2010; 37: 1679-1687.

16. Romesser PB, Qureshi MM, Shah BA, Chatburn LT, Jalisi S, Devaiah AK, Subramaniam RM, Truong MT. Superior prognostic utility of gross and metabolic tumor volume compared to standardized uptake value using PET/CT in head and neck squamous cell carcinoma patients treated with intensity modulated radiotherapy. Ann Nucl Med 2012; 26: 527-534.

17. Burger IA, Vargas HA, Donati OF, et al. The value of (18)F-FDG PET/ $\mathrm{CT}$ in recurrent gynecologic malignancies prior to pelvic exenteration. Gynecol Oncol 2013; 129: 586-592.

18. Bazan JG, Koong AC, Kapp DS, Quon A, Graves EE, Loo BW Jr, Chang DT. Metabolic tumor volume predicts disease progression and survival in patients with squamous cell carcinoma of the anal canal. J Nucl Med 2013; 54: 27-32.

19. Lee SJ, Choi JY, Lee HJ, Baek CH, Son YI, Hyun SH, Moon SH, Kim BT. Prognostic value of volume-based (18)F-fluorodeoxyglucose PET/CT parameters in patients with clinically node-negative oral tongue squamous cell carcinoma. Korean J Radiol 2012; 13: 752 759

20. Miller TR, Grigsby PW. Measurement of tumor volume by PET to evaluate prognosis in patients with advanced cervical cancer treated with radiation therapy. Int J Radiat Oncol Biol Phys 2002; 53: 353-359.

21. Kim BS, Kim IJ, Kim SJ, Nam HY, Pak KJ, Kim K, Yun MS. The prognostic value of the metabolic volume in FIGO stage IA to IIB cervical cancer for tumor recurrence: measured by F-18 FDG PET/CT. Nucl Med Mol Imaging 2011; 45: 36-42.

22. Ciernik IF, Dizendorf E, Baumert BG, et al. Radiation treatment planning with an integrated positron emission and computer tomography (PET/CT): a feasibility study. Int J Radiat Oncol Biol Phys 2003; 57: 853-863.

23. Showalter TN, Miller TR, Huettner P, Rader J, Grigsby PW. ${ }^{18} \mathrm{~F}-\mathrm{flu}$ orodeoxyglucose- positron emission tomography and pathologic tumor size in early-stage invasive cervical cancer. Int J Gynecol Cancer 2009; 9: 1412-1414.

24. Almuhaideb A, Papathanasiou N, Bomanji J. ${ }^{18} \mathrm{~F}-\mathrm{FDG}$ PET/CT imaging in oncology. Ann Saudi Med 2011; 31: 3-13.

25. Ahmad Sarji S. Physiological uptake in FDG PET simulating disease. Biomed Imaging Interv J 2006; 2: e59.

26. Hricak H. Role of imaging in the evaluation of pelvic cancer. Important Adv Oncol 1991: 103-133.

27. Mitchell DG, Snyder B, Coakley F, et al. Early invasive cervical cancer: tumor delineation by magnetic resonance imaging, computed tomography, and clinical examination, verified by pathologic results, in the ACRIN 6651/GOG 183 intergroup study. J Clin Onco 2006; 24: 5687-5694.

28. Rigon G, Vallone C, Starita A, Vismara MFM, Ialongo P, Putignani L, Signore F. Diagnostic Accuracy of MRI in Primary Cervical Cancer. Open J Radiol 2012; 2: 14-21.

29. Bourgioti C, Chatoupis K, Moulopoulos LA. Current imaging strategies for the evaluation of uterine cervical cancer. World J Radiol 2016; 8: 342-354.

\section{Address for correspondence}

\section{Paulina Cegła}

Department of Nuclear Medicine

The Greater Poland Cancer Centre

Poznan University of Medical Sciences

15 Garbary St.

61-866 Poznan, Poland

e-mail: paulina.cegla@gmail.com

Submitted: 19.12 .2018

Accepted: 4.06.2019 